\title{
ATTACKS OF UNCONSCIOUSNESS IN ASSOCIATION WITH FUSED CERVICAL VERTEBRAE
}

BY

\author{
R. S. ILLINGWORTH \\ From the Children's Hospital, Sheffield
}

(RECEIVED FOR PUBLICATION JULY 11, 1955)

There are more than 140 references in the Quarterly Cumulative Index Medicus to papers on fusion of cervical vertebrae, including the KlippelFeil syndrome. A particularly useful review of the Klippel-Feil syndrome is that by Erskine (1946). He wrote that

\begin{abstract}
'Essential features of the cervical deformity are synostosis of two or more cervical vertebrae and flattening and widening of the vertebrae bodies. A numerical reduction of the vertebrae is an incidental rather than an essential part of the disease, as is spina bifida. There is evidence that the anomaly has a genetic basis. . . Spina bifida is frequently found. It is of a false type, as some of the laminae curve down to meet in the midline in a fused mass in the lower cervical region, so that a triangular opening is found, with the apex directed downward and the base toward the occiput. The triangular deficiency in the arches is covered by a layer of fibrous tissue, and occasionally it extends to the upper thoracic region.'
\end{abstract}

As a result of the fusion of vertebrae there is limitation of mobility together with shortening of the neck. It may be associated with other abnormalities, such as platybasia, narrowing or asymmetry of the foramen magnum, Sprengel's deformity, scoliosis, torticollis, oxycephaly and cervical rib.

Numerous neurological disturbances have been described in association with the Klippel-Feil syndrome. They include syringomyelia, weakness of the arms or legs, attacks of quadriplegia, abducens paralysis, deaf mutism, cholesteatoma of the cerebellum, nystagmus, facial weakness, sensorimotor changes in the arms, and bimanual synkinesia, or mirror movements, whereby every movement of one hand is imitated by the other hand, so that reciprocal movements like the climbing of a ladder are impossible.

Below are accounts of two children seen on account of attacks of unconsciousness. One was obviously an example of the Klippel-Feil syndrome. The other showed no clinical evidence of an abnormality of the cervical spine, but because of the resemblance of his symptoms to those of the child with the Klippel-Feil syndrome a radiograph of the cervical spine was asked for, and an abnormality was found. I have been unable to find any reference in the literature to such a condition.

\section{Case Reports}

Case 1. This was a typical example of the Klippel-Feil syndrome (Fig. 1). She was a girl of 5 years of age with two normal siblings and no family history of a similar

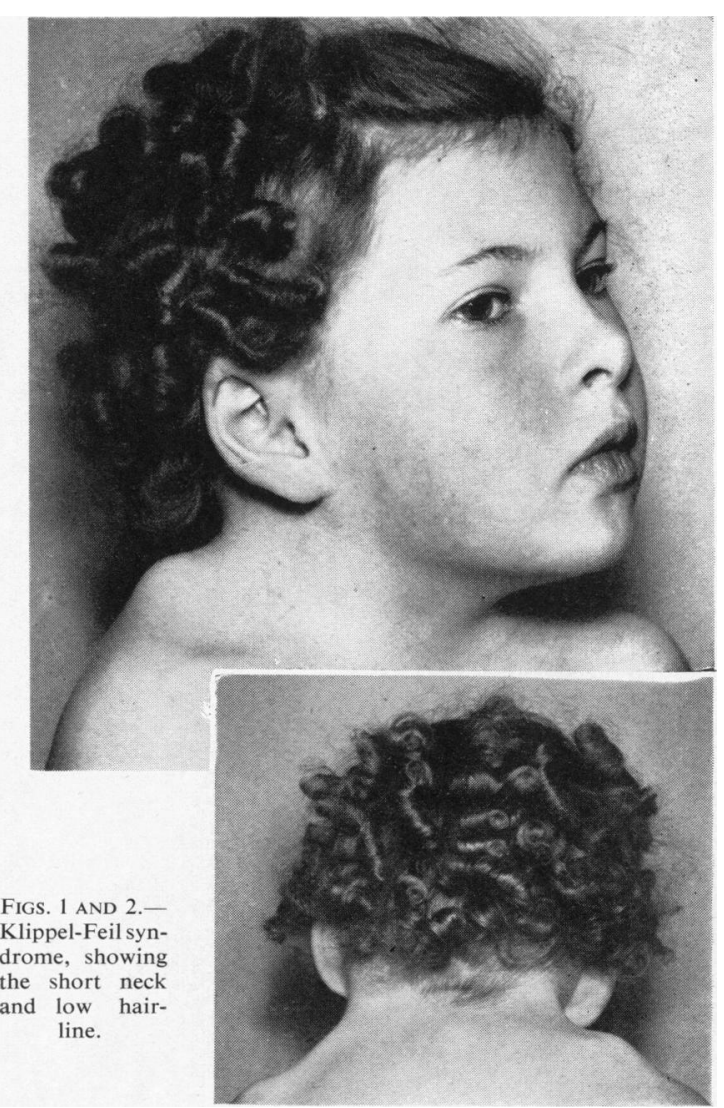


deformity or of epilepsy. She had a short neck with limitation of movement in it, and there was an associated Sprengel's deformity. Her development had been average. She had learnt to walk without support at 16 months, and at the same age had begun to repeat nursery rhymes. Her speech was average.

She had twice lost consciousness in exactly the same circumstances-when she was trying to reach something above her head. In each case she dropped unconscious, white in the face, and did not twitch or feel stiff. After a minute she was normal and running about. There were no abnormal physical signs in the central nervous system, fundi or elsewhere. The radiograph of the cervical spine is shown in Fig. 3. There was a spina bifida of the upper dorsal vertebrae, with a congenital deficiency of the right halves of some of the cervical vertebrae. The bodies of the cervical spine, which was foreshortened, were completely fused. The right scapula was elevated, and there was a congenital absence of the first left rib. The upper two dorsal vertebrae were also fused.

It was assumed that the attacks of unconsciousness were associated with the abnormality of the spine, and no specific treatment was prescribed.

She was seen again at the age of $8 \frac{1}{2}$ years. She had had a third attack of unconsciousness two years and a fourth a year previously. On one occasion she was having breakfast and on the other she was being dressed. The parents were not clear exactly what movement the girl performed immediately before the attacks. In each case she was unconscious for one or two minutes, and was pale, perspiring, but not twitching. It was felt that

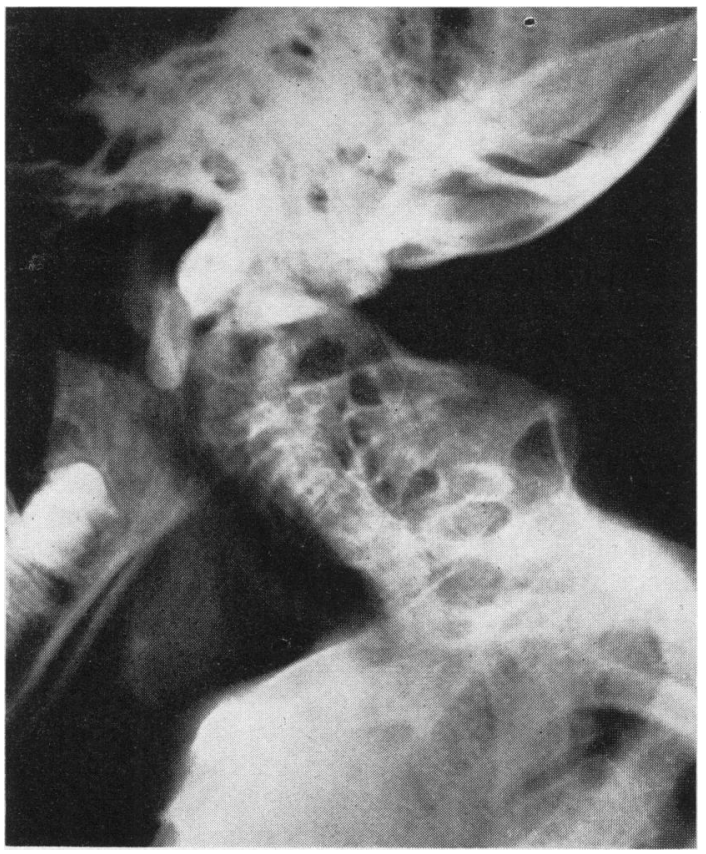

FIG. 3.-Case W.B.: Cervical spine. these two attacks might have been epileptic in origin, but the electroencephalogram was entirely normal.

Case 2. This boy (Fig. 4) was referred at the age of 4 years by Dr. Steiner on account of attacks of unconsciousness following injuries to the back of the head.

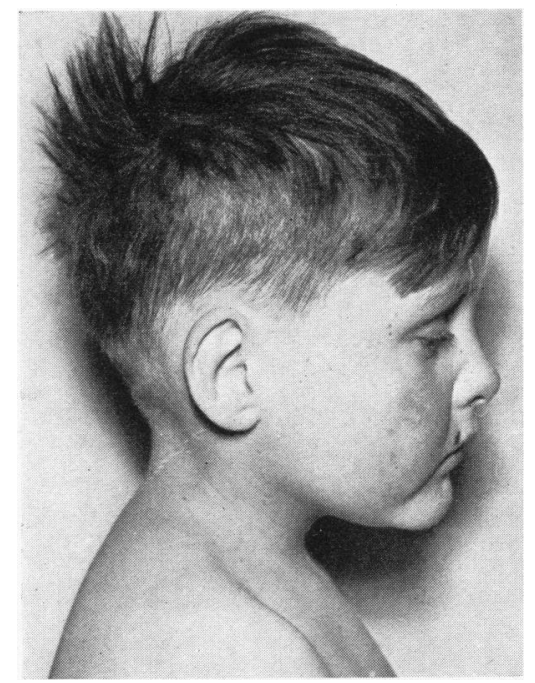

FIG. 4.-Case J.R., showing apparently normal neck.

The boy was adopted, and it was therefore impossible to obtain a family history.

The story was that whenever he had a knock on the back of the head he became unconscious. The first attack was at the age of 7 or 8 months. He had just begun to sit up, without help, and on one occasion he fell over backward and became unconscious. He was cold and clammy, and remained unconscious for five to 10 minutes. There was no stiffness or twitching. The adopting mother thought that he was dead. He recovered consciousness, was dazed for a few seconds, and then behaved normally. From that time onwards there were at least 12 occasions on which he had exactly similar attacks immediately following an injury to the back of the head. He never had any attack without such an injury. The mother was convinced that the unconsciousness never preceded the falls. On one occasion he collided with a boy, hitting the back of the head, and fell unconscious. On many other occasions he had injuries to the front or side of the head, but never became unconscious. On one occasion he fell off his tricycle on to a concrete path and hurt the front of his head severely, much more severely than he had ever been hurt on the back of his head, but he did not become unconscious. Immediately after recovering consciousness after each attack, he did not go to sleep, but got up and went on playing as if nothing had happened. There is no breath-holding at the beginning of the attacks and there is no cyanosis, stiffness, twitching or incontinence. Owing to the attacks he is not allowed to go out into the playground at school to play. 


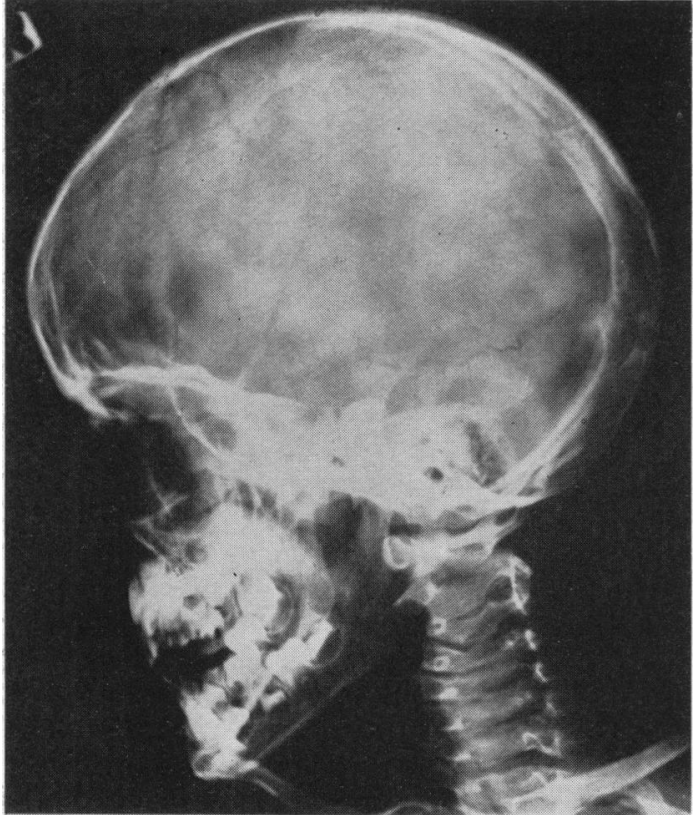

Fig. 5.-Case J.R., radiograph of the skull and cervical spine. The skull is apparently normal. Fusion of second and third cervical vertebrae is shown.

There was no history of headaches, vomiting, easy bruising or temper tantrums. He was a boy of average

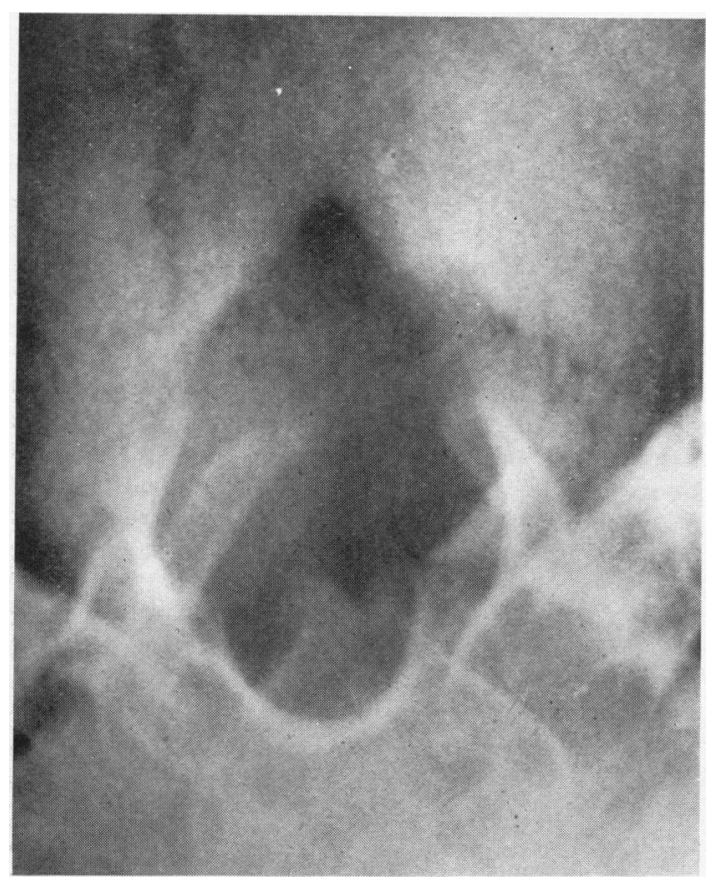

FIG. 7.-The abnormal foramen magnum in Case J.R.

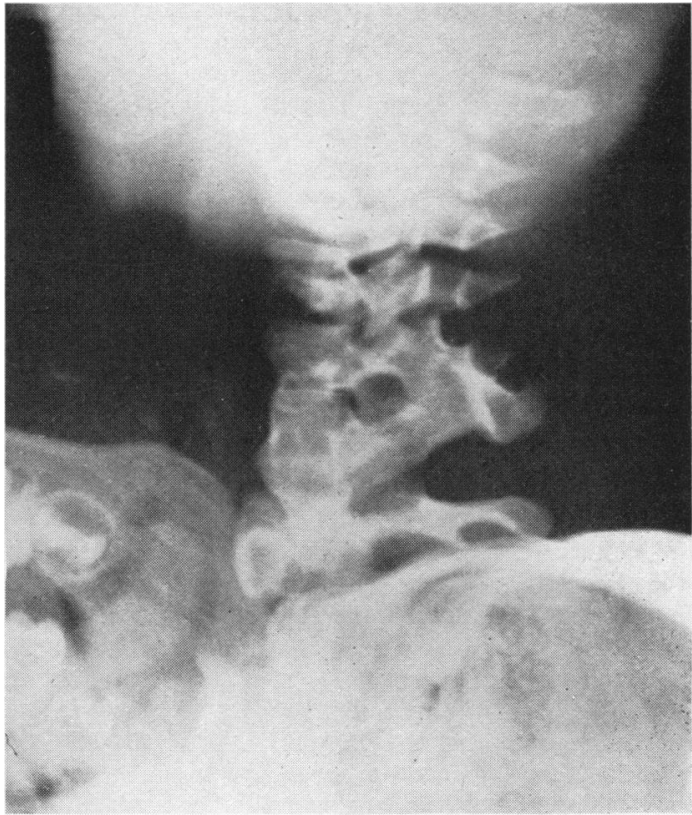

Fig. 6.-Enlarged view of fused cervical vertebrae of Case J.R.

intelligence, who had developed normally. He had begun to walk without help at the age of 15 months. He had acquired full sphincter control, day and night, by the age of 3 .

On examination no abnormality was found. The fundi were normal. The pulse rate was 64 per minute. The cerebrospinal fluid was normal. The radiograph of the skull was normal, but the radiograph of the cervical spine showed fusion of the laminae and spinous processes of the second and third cervical vertebrae (Figs. 5-7). The foramen magnum was enlarged backwards. There was a spina bifida occulta of the atlas. A spinal myelogram did not add any information. The haemoglobin was normal $(14 \cdot 1 \mathrm{~g}$. per $100 \mathrm{ml}$.). Only after the radiograph of the cervical spine had been seen was it thought that there was a very slight limitation of full flexion of the neck.

The electroencephalogram was normal. Movement of the head from full flexion to extension and vice versa had no significant effect on the electrical activity of the brain. The electrocardiogram was normal. Sudden flexion of the neck did not precipitate an attack, but we did not try the effect of hitting the boy on the back of the head.

\section{Discussion}

In an extensive search of the literature $I$ was unable to find a reference to attacks of loss of consciousness in persons with anomalies of the cervical spine. The problem was referred to Professor A. J. E. Cave, of the Department of 
Anatomy, St. Bartholomew's Hospital Medical College, London, for advice. He pointed out that the only common factor in the two children seemed to lie in sudden interference with medullary activity, either mechanical or vascular. He felt that the attacks of unconsciousness were most unlikely to be of vascular origin, because of the remarkable way in which arteries are 'able to fend for themselves' in the presence of anomalies of bone. He thought that the attacks were much more likely to be of mechanical origin. He commented, concerning the second case, the boy J.R.:

'The fusion of the neural arches of cervical vertebrae 2 and 3 is by itself insignificant. The radiographs show, however, an anomalous foramen magnum outline, a dorso-median extension or notch which is not infrequently encountered in cases of congenital defect of the cranio-spinal region. It seems that the medial ends of the neural arch moieties of the atlas encroach somewhat upon the customary vertebral arch outline, and at 6 years one would have expected their mid-dorsal union, incompletely at least. If this is so, the median enlargement of the posterior border of the foramen magnum may be in the nature of a compensatory accommodation of the medulla, which extends inferiorly to the upper edge of the atlantal posterior arch. So far as I can judge, this child manifests some unusual congenital condition of the occipitoatlantal region, in the nature of a posterior modification of skeletal parts to accommodate the medulla. Falls or blows to the occipital region must bring the medulla sharply and intimately into contact with the posterior parietes of the occipitovertebral region, with resulting black out. As regards the girl, W.B., the radiograph shows a very disorganized cervical spine, and I doubt not that the foramen magnum region is also congenitally anomalous.'

He went on to remark that we have no assurance that the central nervous system is normal in such cases, adding: 'It would not be surprising if medullary defect should accompany constitutional defect of the relative and enclosing skeletal parts'.
It is interesting to note that the reaction of the two children was identical-sudden unconsciousness without stiffness or convulsive movements, immediately followed by normal activity and running about without drowsiness. In the girl the third and fourth attacks suggested the possibility of epilepsy, and that diagnosis cannot be entirely excluded in spite of the normal E.E.G. In the case of the boy there is nothing to suggest epilepsy, and it is clear from the history that all attacks immediately followed injuries to the head, and that the injuries did not result from an attack of unconsciousness. The cause of the attacks remains obscure, but Professor Cave's suggested explanation, namely sudden compression of the medulla, seems to be the most likely one.

\section{Summary}

Two children with attacks of unconsciousness associated with anomalies of the cervical spine are described. In one case, a typical example of the Klippel-Feil syndrome, attacks of unconsciousness followed extension of the neck: in the other case, attacks of unconsciousness followed sudden flexion of the neck caused by blows on the back of the head. The children were pale and limp in the attacks, without convulsive movements, and ran about normally immediately on recovery of consciousness.

The possible anatomical cause of the attacks is discussed.

My especial thanks are due to Professor A. J. E. Cave for going to a great deal of trouble in searching the literature, and examining his notes, correspondence and museum specimens to find an anatomical basis for the attacks described, and for giving permission to quote his letter.

I also wish to thank Dr. T. Lodge, radiologist, for the radiographs, Dr. J. W. Warboys for the E.E.G.s, Drs. J. W. Steiner and D. E. Hobday for referring the children to me, and to Professor F. Davies for his advice.

REFERENCE

Erskine, C. A. (1946). Arch. Path., Chicago, 41, 269. 